\title{
The Meaning and Intensity of the Near-Death Experience
}

\author{
James M. Sahlman, Ph.D. \\ Max C. Norton, Ph.D. \\ California State University-Stanislaus, Turlock, CA
}

\begin{abstract}
This is the second in a three-part study exploring the hypothesis that near-death experiencers (NDErs) assign the meaning of the NDE by using causal (effect) and semantic (affect) attributions. To test this hypothesis, 32 spontaneous verbal accounts of NDEs were analyzed. Each statement comprising the account was coded and classified according to the six attributional types in the Norton-Sahlman matrices of attributional classification. On the bases of these findings, we conclude that NDErs abstract the most significant aspects of meaning from their experiences by the use of attributions expressing the purposes of the experience and the intentions of the participants. Second, the meaning and intensity of the experience derives from attributions of both effect (causality) and affective significance: the assignment of subjective meaning to objects and events (affect). Third, the findings demonstrate that there are significant changes in NDErs' overt and affective states, reinforcing our argument that meaning and intensity of the NDE is a function of how the experiencer assigns causation, in addition to the affective significance that the experiencer places on the events constituting the NDE.
\end{abstract}

The purpose of the present study is to explore through attributional analysis the process by which individuals assign the meaning of the near-death experience (NDE), and how NDErs communicate these cogitations to other people (Norton and Sahlman, 1995).

James M. Sahlman, Ph.D., is Instructor in Communication Studies at California State University-Stanislaus, Turlock, California, where Max C. Norton is Professor Emeritus of Communications Disorder and Psycholinguistics and Chair, Educational Endowment Committee, California State University Emeritus Faculty Association. Reprint requests should be addressed to Dr. Sahlman at the Department of Communication Studies, California State University-Stanislaus, 801 West Monte Vista Avenue, Turlock, CA 95382. 
The study will explore the hypothesis that the experiencer assigns the meaning of the near-death experience through interpretive usage of causal explanations and statements of affective significance. According to our theory of interpretive usage, the meaning of an experience is expressed through the assignment of single and multiple causes of behavior (effect) and subjective affects to objects and experiences as a function of what the individual feels or believes to be true rather than what is objectively verifiable (affective significance).

\section{Definitions}

\section{Meaning}

For the purpose of the study, the term meaning is defined operationally as the total change in the state of the experiencer, either overt or mental, that results from the interpretation of the experience.

This definition is derived from the theory of interpretive usage:

In its interpretive usage, the meaning of an utterance, to some specific person (perceiver) in some specific context and environment is the total change of state of that person (overt or mental) on receipt of that utterance (Cherry, 1966, p. 307)

This theory implies that an experiencer will interpret the meaning of an event by placing it in a context that is most relevant to his/her background of experience and belief (Norton and Sahlman, 1995).

\section{Intensity of Experience}

The intensity of the experience is defined in terms of the strength of the relationship between causal factors, and the affective significance of the experiencer's belief system for the perception of the events constituting the experience (affective states). We posit that the intensity of an experience is demonstrated by the strength of the relationship between and among attributional types. 


\section{Veridicality of Experience}

Identifying the causal consequences of events is the basis for the establishment of the veridicality of the experience. Furthermore, the degree to which the experiencer believes in the veridicality of his or her perceptual knowledge is also indicative of the intensity of the experience: the more intense the experience, the greater the consequences.

\section{Attributional Awareness}

Attributional awareness deals with the assignment of singular or multiple causes for events and affective significance to an experience. In making attributional statements, the experiencer is offering explanations of the nature and purpose of a given experience.

Attributional statements are based upon social and self-perception and are central to the cognition of meaning and the development of one's psychological epistemology or self-knowledge, a knowledge "that one's beliefs and judgments are veridical" (Kelly, 1973, p. 107). We argue that while some NDErs are willing to accept on faith the profound nature of the near-death event, they nevertheless desire to determine the meaning of the experience. It follows, therefore, that for the experiencer to abstract meaning from an experience, he or she must understand the relationship between cause and effect (that is, attributional awareness).

\section{Method}

\section{Selection of Samples}

Thirty-two near-death experiences were selected for analysis; 17 participants were males and 15 were females. NDE accounts were collected from three sources. An initial set of accounts was collected from individuals attending the International Association for NearDeath Studies (IANDS) 1995 National Conference in Hartford, CT. Accounts from that conference were either written down and submitted to one of us (M.C.N.), or transcribed from purchased cassette tapes made available by IANDS, containing recorded testimony of NDEs. Another set of NDE accounts was collected from materials 
published in Vital Signs, the IANDS quarterly newsletter. The final set of NDE accounts was comprised of an "opportunity sample," wherein individuals from local chapters of Friends of IANDS or from local communities expressed an interest in providing their testimonies to the authors. For many of the accounts, gender was the only demographic variable made available to us. For this reason, we cannot report in this article mean age of respondents or other potentially valuable demographic information.

No restrictions were placed on the length or content of any of the accounts collected. Samples were collected without regard to formatting or to any rules as to how to describe the NDE. In short, we hoped to have people tell us about their experiences rather than influencing them in what they might perceive we wanted.

\section{Procedure}

A frequency count of all statements in the account samples was calculated and coded according to attributional type. For the purpose of this study, attributional statements were classified as causal (effect) and semantic (affect). It should be noted that effect and affect are not mutually exclusive; indeed, they may be interdependent (Norton and Sahlman, 1995), so that two types of attributions may be expressed in the same statement. In this regard, Fritz Heider wrote:

In distinguishing between the attribution of an event to a direct causal source, and the attribution of a positive or negative quality to an experience, we do not mean that causal attribution and the affective significance of an event do not influence each other. Actually, they are highly interdependent. (1958, p. 170)

\section{System of Classification}

The system of classification was adapted from the Norton-Sahlman (Norton and Shalman, 1995) matrices of causal and semantic attributional classifications. Each statement comprising a given NDE account was coded according to the following six attributional types: (1) purpose and intention (PI); (2) past conditions (PC); (3) future actions/consequences (FA); (4) demand for change (DC); (5) affective significance (AS); and (6) valuational consequences (VA). Non-attri- 
bution statements (NA) were also coded. The criteria for classification of statements were as follows:

Purpose and intention (PI). These are statements that address questions concerning the purpose of events and the intentions of the actors: "Why did the event occur?" [purpose] or "Why did certain people appear?" [intention].

In the study of personal causality, intentional behavior is the central factor inasmuch as it is associated with an invariant effect, or goal. That is to say, the actor controls the means-end relationship. The Biblical story of Job delineated this operational definition of purpose and intention: that narrative addressed the question of why a loving God would create a world in which there was so much suffering, and why would He allow it to fall on those who least deserve it. If God is the cause, the next question becomes: "Why? What were God's intentions?" However, in the Biblical account, God did not reveal His intentions, and for this reason, Job's three companions attributed the cause of Job's suffering to him.

Some statements imply both intention and purpose, as in the following: "My mother said: 'I cannot keep you in this heavenly realm, for it is not your time to die." The verb forms "can" (or "cannot") and "try" denote both intention and purpose (Norton and Sahlman, 1995).

In assigning personal causation, if the source is not intentionally motivated, the act is deemed nonpurposeful. For example, in the statement "The boy [source] left the soap on the shower floor, and his brother slipped on it and hurt himself," the consequences were not predicted beforehand. Also, environmental factors might have intervened, leading to a wide range of effects.

We can therefore conclude that unintentional acts lead to unintentional consequences, or effects. For example, if as a consequence of seeing his brother injured, the boy learned to put the soap in the dish instead of on the floor, the pursuant act would be purposeful in the respect that the source was consciously controlling the means-end relationship. The goal thus has become invariant and the meaning of the original act was made clear to the source (that is, the boy).

Past condition (PC). The previous discussion raises the question of the onus of responsibility for past causal actions. To whom should we attribute responsibility for negative and positive causal acts? In the statement "As a result of my past life [causal actions], I can now understand why my loved ones met me and gave me this life review [causal consequence]," there is an account of past causal conditions underlying the experience, and an assignment of responsibility for 
the consequences (that is, my past life). Attribution of responsibility for the conditions leading up to the life review is clearly stated.

Future consequences (FC). There are dispositional properties in this type of attribution that imply a necessity for certainty and predictability (that is, to control events). It is for this reason that the consequences for future gain or loss including necessity, desire, and the need for future rewards and benefits are imbedded in this type of attribution. For example, in the statement "You must reorganize your life so that you can become worthy to return to this heavenly place," the future consequences of the experience are clear (that is, parameters are placed on future decisions). In the statement "If you repent and become like a little child and ask for Christ to enter your heart, you will become as a little child . . . and come back into the spirit world and have joy and love forever," the future consequences are made clear: "reorganize your life and you will receive a future reward." However, the cause-effect relationship can be inverted as follows: "Any rewards in a future life will be the result of 'becoming as a little child."

Demands for change (DC). This type of attribution contains demands for change based upon present conditions. It differs from the above inasmuch as it includes imperatives of personal necessity and forbiddance. In the statement "You must go back because this is not your time to die," the actors, or participants, in the NDE make certain demands for change based upon an existent set of conditions that must be altered.

Affective states (AS). An affect is the assignment of connotative or subjective meaning to objects and experiences. These are known as attributes. Affective meanings are assigned to objects and experiences on the basis of what the experiencer feels or believes to be true, rather than what is objectively verifiable. For example, in the statement "I felt an inexpressible joy in knowing the love that emanated from the personage of light," the individual attributes his or her joy to a belief about the personage of light.

The statement "I looked down upon the accident scene and a hand touched me and I turned to see there that a peace and serenity and blissful feeling was coming from the Lord Jesus Christ," delineates the significance of affect on the interpretation of experience.

In the following statements, the experiencer assigns affects of love, truth, and light to his or her experience based upon what were believed to be the attributes of Christlike behavior: 
I knew without any doubt that a universe was radiating with love of Christ and my very soul was filled with its joy and goodness. Then I heard a voice addressing me with great reassurance, telling me that I was safe from the evils of the world because of light of truth, the love of Christ.

Valuative affective consequences (VC). These attributions assign positive or negative values to objects, persons, conditions, and experiences. These are manifested as statements implying a comparative or an absolute value. For example, in the statement "I was surrounded by pure love," an absolute value is assigned to the experience.

In the statement "Being in the presence of the personage of light was more joyful than anything I had experienced on earth," a comparative value is attributed to the experience. The valuative consequences are clear: the joy was greater than any joy experienced in the pre-NDE state. However, in the statement "Just being in the presence of the personage of light filled me with an indescribable joy" the experiencer is incapable of assigning a comparative value to his or her experience. This type of attribution is typical of experiences involving transcendental affective states.

\section{Results}

Data Analysis

The chi-squared $\left(\chi^{2}\right)$ goodness-of-fit test was employed to determine whether or not the frequencies observed for each of the attributional categories departed significantly from the frequencies expected from an hypothesis of equal likelihood. The results, shown in Table 1, suggest the operation of a nonchance factor.

On the basis of this finding, we conclude that NDErs abstract the most significant aspects of the meaning of the experience by the use of statements, or attributions, of purpose, intention, and future consequences that follow. It is important to note that for those experiencers who scored higher than the mean on these attributions, the intensity of the experience was emphasized by the causal explanations concerning the reasons the experience occurred and the intentions of the participants or actors in the experience. The following statement is typical of this type of causal explanation: "What was the reason for the near-death experience? I wish I could remember. Why do things happen? I don't know what the answers were." 
Table 1

Observed and Expected Frequencies of Attributions

\begin{tabular}{|c|c|c|c|c|c|c|c|}
\hline & \multicolumn{7}{|c|}{$\begin{array}{l}\text { Type of Attribution (see text for } \\
\text { explanation of abbreviations) }\end{array}$} \\
\hline & $P I$ & $P C$ & $F A$ & $D C$ & $A S$ & $V A$ & Total \\
\hline Observed Frequency $=0$ & 183 & 171 & 107 & 86 & 94 & 40 & 681 \\
\hline Expected Frequency $=\mathrm{E}$ & 114 & 114 & 114 & 114 & 114 & 114 & 681 \\
\hline Observed-Expected $=\mathrm{O}-\mathrm{E}$ & 69 & 57 & -7 & -28 & -20 & -74 & 0 \\
\hline $\begin{array}{l}\text { (Observed-Expected })^{2} \\
\quad=(\mathrm{O}-\mathrm{E})^{2}\end{array}$ & 4761 & 3249 & 49 & 784 & 400 & 5476 & 14,719 \\
\hline
\end{tabular}

Second, for those experiencers who scored higher than the expected frequency values in the use of attributions for purpose, intent, future action, and demands for change, there are significant changes in their overt and affective mental states. We conclude that such changes carry over into the post-NDE environment and significantly alter the experiencer's attitudes and behaviors.

Third, the results suggest that intentionality, or attribution of intention, is an important factor governing post-NDE orientation. This is revealed in the statistically significant number of statements utilizing the verbal expressions "I can," "I will," "I cannot," and "I will not," in which the experiencer reveals a need for self-actualization and motivation. The following statement is typical of the motivational factors that characterize attributions of personal intention and the future consequences that result, or of future action, and the future consequences that result from them:

I know now why my grandfather appeared to me; he wanted to let me know the meaning of life and death and what to expect, but I cannot know if I will ever understand it fully, there are so many things out there to cope with."

\section{Intercorrelations Between Attributional Types}

We performed a correlational analysis of attributional types to determine the interrelationship between attributional statements and 
Table 2

Correlations Among Attributions (see text for explanation of abbreviations)

\begin{tabular}{llllllll}
\hline & $P I$ & $P C$ & $F A$ & $D C$ & $A S$ & $V A$ & Total \\
\hline PC & .23 & & & & & & \\
FA & $.54^{* *}$ & .23 & & & & & \\
DC & $.72^{* *}$ & .25 & $.55^{* *}$ & & & & \\
AS & .07 & .40 & .04 & .07 & & & \\
VA & -.08 & .12 & -.20 & .04 & .37 & & \\
Total & .18 & $.65^{* *}$ & .05 & .07 & $.68^{* *}$ & .22 & \\
NA & -.11 & $.47^{*}$ & -.21 & -.23 & $.59^{* *}$ & .18 & $.93^{* *}$ \\
\hline${ }^{*} p<.01$. & & & & & & \\
$*_{p}<.001$. & & & & & &
\end{tabular}

whether a given attribution was directly influenced by another. Table 2 presents correlation coefficients between the types of attributions.

The data presented in Table 2 show a strong relationship between attributions of demands for change (DC) and purpose and intention (PI). These data reinforce the finding revealed in the chi-squared calculations that experiencers tend to relate the need for changes in future lifestyle to the purpose of the experience. The following attributional statement delineates the relationship between purpose and demand for change in life goals: "It was then that I realized that my life on earth had a purpose: that I must return to the world as I found it because it was part of the plan which was to teach others how to live so as to overcome the suffering of mortality."

These correlations also reveal the relationship between personal necessity for change and demand for change in future lifestyle: "I had learned that everything that I was to do from then on was necessary for the future well-being of the world in general and of course for my own salvation."

\section{Conclusions}

The findings suggest that the meaning of the near-death experience is a direct function of the relationship between purpose, intention, and the need for changes in the attitude and overt behavior of the 
experiencer following an NDE. They confirm our basic postulate that the meaning of the near-death experience can be operationally defined as the behavioral changes that occur in the organism as a function of interpretive usage (that is, of his or her interpretation of the experience). They also demonstrate that changes in behavior of the experiencer following an NDE is positively reinforced by the intensity of the experience.

Second, the meaning and intensity of the experience derives from the frequency of attributions of both effect and affect. This conclusion suggests the need to explore further the relationship between objectively verifiable causality and the experiencer's belief system.

Third, the results indicate that affect, or affective significance, and causality, or causal attribution, are interdependent in the respect that they both influence future action, as demonstrated by the need for change in post-NDE attitudes and goals.

These findings reaffirm our contention that the meaning of the near-death experience is a direct function of how the experiencer interprets causation and the affective significance that the experiencer places on the objects and events comprising the NDE.

\section{References}

Cherry, C. (1970). On human communication. Cambridge, MA: M.I.T. Press.

Heider, F. (1958). The psychology of interpersonal relations. New York, NY: Wiley.

Kelly, H. H. (1973). The process of causal attribution. American Psychologist, 28, $107-$ 128.

Norton, M. C., and Sahlman, J. M. (1995). Describing the light: Attribution theory as an explanation of the near-death experience. Journal of Near-Death Studies, 13, 167-184. 